\title{
'Die richtigen Informationen: immer und überall
}

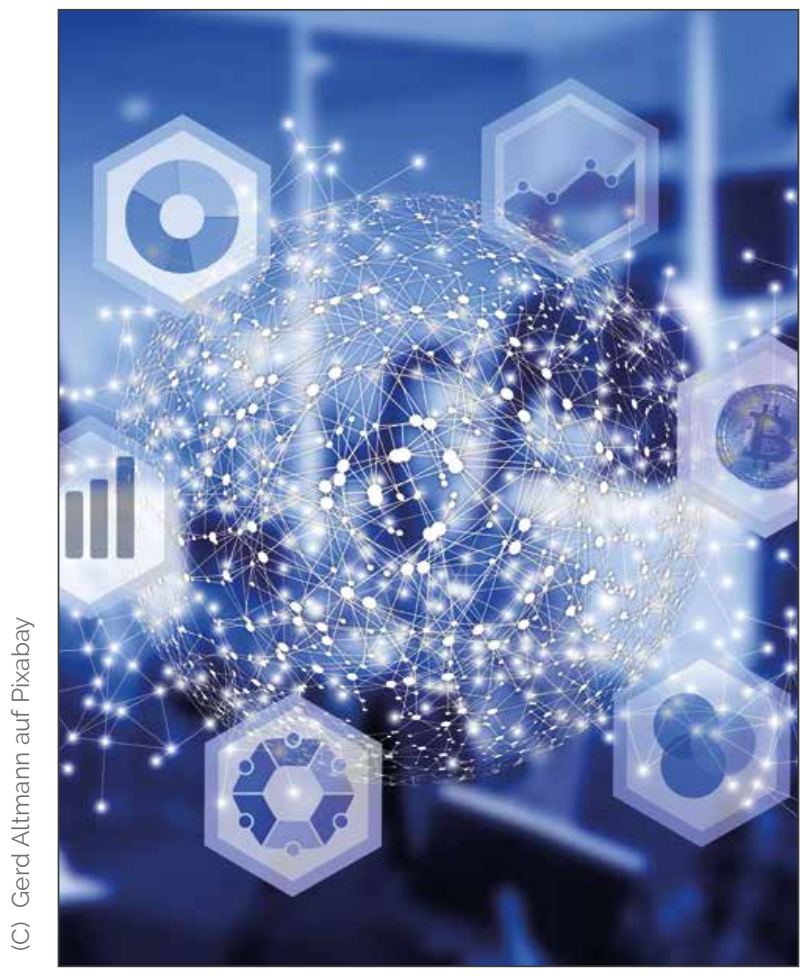

„Projektdokumentationen? Liegen im Aktenschrank. Informationen rund um Urlaub und Abwesenheiten? Am besten bei den Kollegen im Personalbüro vorbeigehen. Und die aktuellen Forecast-Zahlen? Da hat nur der Controller Zugriff, aber er ist erst nächste Woche wieder am Platz. Bis dahin müssen wir warten oder mit Schätzungen arbeiten." Analoges Informations- \& Wissensmanagement wird den Anforderungen einer smarten Gesellschaft schon lange nicht mehr gerecht. Doch erst im Pandemie-bedingten Remote-Modus wurde der tatsächliche Status quo des organisationalen Datenhandlings offenbar: Ein zeit- und ortsunabhängiger Zugriff auf das Unternehmenswissen ist für die Arbeit im Office 4.0 unabdingbar. Nur wer in Echtzeit valide Informationen im Firmennetzwerk abrufen kann, ist für Kollegen und Mitarbeiter, für Kunden und Auftraggeber aussagefähig.

Zudem setzt intelligentes Dokumentenmanagement wertvolle Ressourcen frei. Denn mit der Digitalisierung des Datenbestands geht in aller Regel auch eine Automatisierung von Routineprozessen einher. Ob Rechnungseingang oder Postausgang, Einkaufsworkflows oder Bestellvorgänge: Die erforderlichen Daten werden vollautomatisch analysiert, kategorisiert und zugeordnet. So lassen sich ohne menschliches Zutun Folgeprozesse anstoßen und Verantwortliche informieren. Sogar mögliche Fehler werden vom System erkannt und im Rahmen eines Frühwarnsystems gemeldet.

Doch in der Praxis sind die meisten Unternehmen - wider ihrer eigenen Einschätzung - noch lange nicht im Office 4.0 angekommen. Wie der Weg dorthin aussehen kann, welche Voraussetzungen dafür geschaffen werden müssen und welche Tools sich für nachhaltiges Wissensmanagement besonders eignen, das lesen Sie im aktuellen Titelthema „Die Informationsflut im Griff: Daten erfassen, verwerten und wiederfinden" ab Seite 16.

Neben dem Wandel hin zum smarten Unternehmen, das auch im Remote-Modus reibungslos funktioniert, versuchen viele Organisationen derzeit, agiler zu werden. Sie wollen weg von starren Hierarchien und stattdessen autonome Taskforces etablieren, die schnell und flexibel auf die sich ständig wandelnden Rahmenbedingungen reagieren können. Ob sich dieser Change auch für Sie lohnt und wie Sie inn umsetzen, lesen Sie in unserem Special „Scrum \& Co." ab Seite 44.

Ihr

Oliver Lehnert

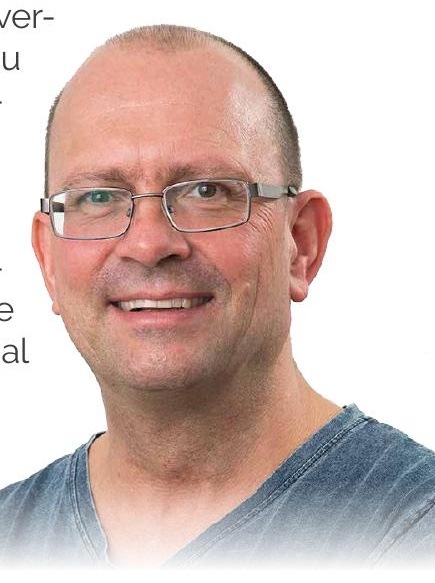

